\title{
Immunohistochemical detection of BCL-3 in lymphoid neoplasms: a survey of 353 cases
}

\author{
Ozlem Canoz*, George Z Rassidakis, Joan H Admirand and L Jeffrey Medeiros \\ Department of Hematopathology, The University of Texas MD Anderson Cancer Center, Houston, TX, USA
}

\begin{abstract}
The $b c l-3$ gene at chromosome $19 q 13$ encodes a member of the $1 \kappa B$ family involved in regulating the NF $\kappa B$ pathway. Originally identified by its involvement in the rare $t(14: 19)(q 32 ; q 13), B C L-3$ expression has never been analyzed in a wide variety of lymphomas. We assessed BCL-3 expression in 353 cases of non-Hodgkin lymphoma and Hodgkin lymphoma using formalin-fixed, paraffin-embedded tissue specimens, a monoclonal antibody specific for BCL-3, and immunohistochemical methods. Of 172 B-cell lymphomas, 10 (6\%) were positive for BCL-3, including six of $23(26 \%)$ diffuse large B-cell lymphoma, one of $17(6 \%)$ small lymphocytic lymphoma, one of $26(4 \%)$ follicular lymphoma, and two of $49(4 \%)$ mantle cell lymphoma. All other B-cell neoplasms were negative, including marginal zone lymphoma ( $n=24,11$ extranodal, nine nodal, four splenic), Burkitt lymphoma $(n=10)$, lymphoplasmacytic lymphoma $(n=10)$, lymphoblastic lymphoma $(n=8)$, and plasmacytoma $(n=5)$. Of $111 \mathrm{~T} / \mathrm{NK}$-cell lymphomas, $25(23 \%)$ were positive for BCL-3, including 13 of $40(32 \%)$ anaplastic large-cell lymphoma, three of $10(30 \%)$ angioimmunoblastic T-cell lymphoma, two of eight $(25 \%)$ extranodal NK/T-cell lymphoma of nasal type, three of $12(25 \%)$ mycosis fungoides, one of five $(20 \%)$ enteropathy-type T-cell lymphoma, and two of $21(10 \%)$ peripheral T-cell lymphoma unspecified. All other T-cell neoplasms were negative, including lymphoblastic lymphoma $(n=6)$, prolymphocytic leukemia $(n=6)$, and subcutaneous panniculitis-like T-cell lymphoma $(n=3)$. Of 70 Hodgkin lymphomas, of all types, $29(41 \%)$ were positive for BCL-3. The relatively high frequency of BCL-3 expression in some non-Hodgkin and Hodgkin lymphoma types raises the possibility that BCL-3 is involved in the pathogenesis of these tumors, and may be a target of new therapies.
\end{abstract}

Modern Pathology (2004) 17, 911-917, advance online publication, 23 April 2004; doi:10.1038/modpathol.3800140

Keywords: BCL-3; immunohistochemistry; non-Hodgkin lymphoma; Hodgkin lymphoma

The bcl-3 gene, located at chromosome 19q13, was originally identified by its involvement in the $\mathrm{t}(14: 19)(\mathrm{q} 32 ; \mathrm{q} 13)$. In this translocation, $b c l-3$ is juxtaposed with the immunoglobulin heavy chain gene locus at $14 \mathrm{q} 32 .{ }^{1}$ The $\mathrm{t}(14 ; 19)$ was first described in $1983^{1}$ and 2 years later was reported to be associated with chronic lymphocytic leukemia/small lymphocytic lymphoma with atypical morphology. ${ }^{2}$ McKeithan et $a l^{3}$ first cloned the bcl-3 gene in 1987.

BCL-3 encodes an I $\kappa$ B-like protein that regulates $\mathrm{NF} \kappa \mathrm{B} /$ Rel transcription factors. ${ }^{4}$ The mammalian $\mathrm{NF} \kappa \mathrm{B} / \mathrm{Rel}$ family consists of five known members:

Correspondence: Dr LJ Medeiros, MD, Department of Hematopathology, Box 72, University of Texas MD Anderson Cancer Center, 1515 Holcombe Blvd, Houston, TX 77030, USA.

E-mail: jmedeiro@mail.mdanderson.org

* Dr Canoz did this work as a visiting pathologist at MD Anderson Cancer Center.

Her current address: Department of Pathology, Erciyes University Medical Faculty, Kayseri, Turkey.

Received 24 November 2003; revised 26 January 2004; accepted 28 January 2004; published online 23 April 2004 p50/p105, p52/p100, RelA (p65), c-Rel, and RelB. ${ }^{4}$ These proteins are normally found in the cell cytoplasm, complexed with inhibitory I $\kappa \mathrm{B}$ molecules, but when $\mathrm{I} \kappa \mathrm{B}$ proteins are degraded free NF$\kappa \mathrm{B} /$ Rel family proteins can translocate to the nucleus and activate expression of a variety of genes. The $\mathrm{I} \kappa \mathrm{B}$ family, in addition to BCL-3, is composed of four other members, $\mathrm{I} \kappa \mathrm{B} \alpha, \mathrm{I} \kappa \mathrm{B} \beta, \mathrm{I} \kappa \mathrm{B} \varepsilon$, and $\mathrm{I} \kappa \mathrm{B} \gamma$. BCL-3 is unique among the members of this family because it is located predominantly in the nucleus, it interacts with p50 and p52 homodimers of $\mathrm{NF} \kappa \mathrm{B}$ and it binds to other nuclear proteins (e.g. JAB-1) that can bind to transcription factors (e.g. C-JUN). ${ }^{5}$ These data suggest that BCL-3 is an adaptor protein between NK- $\kappa \mathrm{B}$ p50/p52 and other transcriptional regulators. ${ }^{5}$

The $t(14 ; 19)$ or $b c l-3$ gene rearrangement has been reported rarely in non-Hodgkin lymphomas, in approximately 35 cases, mostly in cases of chronic lymphocytic leukemia/small lymphocytic lymphoma, and less frequently in cases designated as follicular lymphoma, diffuse large B-cell lymphoma, Burkitt-like lymphoma, and one case of acute 
biphenotypic leukemia. ${ }^{6-12}$ Although the $\mathrm{t}(14 ; 19)$ is rare, BCL-3 expression has been shown in a few types of non-Hodgkin lymphoma not known to carry the $\mathrm{t}(14 ; 19)$. For example, two recent studies have shown high levels of BCL-3 expression in ALKpositive anaplastic large-cell lymphoma. ${ }^{13,14}$ However, presence or absence of BCL-3 expression is unknown for most of the wide variety of lymphoma types defined in the recently published World Health Organization (WHO) classification. ${ }^{15}$

In this study, we used an immunohistochemical method and a commercially available monoclonal antibody specific for BCL-3 to assess for expression in 353 cases of non-Hodgkin lymphoma and Hodgkin lymphoma.

\section{Materials and methods}

\section{Study Group}

A total of 353 lymphomas were collected from the files of the Department of Hematopathology of The University of Texas MD Anderson Cancer Center between 1998 and 2003. The diagnosis of all tumors was based on morphologic and immunohistochemical criteria according to the WHO classification. ${ }^{15}$ The group of B-cell lymphomas included 49 mantle cell lymphoma, 26 follicular lymphoma (seven grade I, nine grade II and 10 grade III), 23 diffuse large B-cell lymphoma, 17 small lymphocytic lymphoma/chronic lymphocytic leukemia, 11 extranodal marginal zone B-cell lymphoma, 10 Burkitt lymphoma, 10 lymphoplasmacytic lymphoma/ Waldenstrom macroglobulinemia, nine nodal marginal zone B-cell lymphoma, eight precursor B-lymphoblastic lymphoma/leukemia, five plasmacytoma, and four splenic marginal zone lymphoma. The group of T-cell lymphomas included 40 anaplastic large-cell lymphoma, 21 peripheral T-cell lymphoma, unspecified, 12 mycosis fungoides, 10 angioimmunoblastic T-cell lymphoma, eight extranodal NK/T-cell lymphoma of nasal-type, six T-cell prolymphocytic leukemia, six precursor T-lymphoblastic lymphoma/leukemia, five enteropathy-type T-cell lymphoma, and three subcutaneous panniculitis-like T-cell lymphoma. The group of Hodgkin lymphoma cases included 43 nodular sclerosis, 13 nodular lymphocyte predominant, 11 mixed cellularity, and three lymphocyte-rich classical. Five cases of reactive follicular hyperplasia were also studied.

Tumors were analyzed using either full tissue sections $(n=217)$ or tissue microarrays $(n=136)$. The tissue microarrays included triplicate or quadruplet tumor cores from all 136 tumors and were constructed using a manual tissue arrayer (Beecher Instruments, Silver Springs, MD, USA) as described previously. ${ }^{16,17}$ All cases were fixed in $10 \%$ buffered formalin, routinely processed, and embedded in paraffin.

\section{Immunohistochemical Methods}

Tissue sections ( 3 or $4 \mu$ m thick) were deparaffinized in xylene and rehydrated in a graded series of ethanols. Heat-induced epitope retrieval was performed. Tissue sections were placed in plastic Coplin jars containing preheated target retrieval solution (DAKO) heated in a household vegetable steamer (Sunbeam-Oster, Model Sunbeam 4713/ $5710,900 \mathrm{~W}$ ) for $35 \mathrm{~min}$, and allowed to cool at room temperature for at least $15 \mathrm{~min}$. We used a monoclonal antibody specific for BCL-3 (clone 1E8, Novacastra, Newcastle upon Tyne, UK) at a dilution of 1:50. Subsequent steps of the immunostaining procedure were performed in a humidity chamber as previously described. ${ }^{18}$ These steps included: (1) blocking of endogenous peroxidase in $3 \% \mathrm{H}_{2} \mathrm{O}_{2}$ in

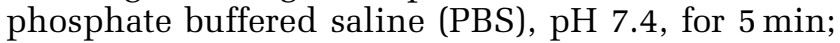
(2) blocking of nonspecific protein-binding sites using protein blocking solution (DAKO) for $5 \mathrm{~min}$; (3) incubation with the primary antibody overnight; and (4) detection using the streptavidinbiotin-peroxidase based LSAB + kit (DAKO) for $2 \times 15$ min. We used $3,3^{\prime}$ diaminobenzidine $/ \mathrm{H}_{2} \mathrm{O}_{2}$ (DAKO) as the chromogen and hematoxylin as the counterstain.

\section{Scoring of Positive Cells}

Only nuclear staining was considered positive for BCL-3, irrespective of intensity, as the protein has been shown to be located predominantly within the nucleus. ${ }^{5}$ At least 500 tumor cells were counted in each case. Positivity was defined as equal to or greater than $20 \%$ positive cells. However, almost all negative tumors were completely negative or tumors had $<5 \%$ positive cells and positive tumors showed a range of positive cells, always over $20 \%$ and, in some cases, over $50 \%$.

\section{Results}

\section{Benign Lymphoid Tissues}

Reactivity for BCL-3 in five reactive tissue specimens was confined to endothelial cells and follicular dendritic cells within germinal centers. Lymphoid cells were negative for BCL-3.

\section{Non-Hodgkin Lymphomas and Hodgkin Lymphomas}

Table 1 summarizes the BCL-3 results in various types of B-cell non-Hodgkin lymphoma. Of 172 B-cell lymphomas, $10(6 \%)$ were BCL-3 positive, including six of $23(26 \%)$ diffuse large B-cell lymphoma, one of $17(6 \%)$ small lymphocytic lymphoma/chronic lymphocytic leukemia, one of $26(4 \%)$ follicular lymphoma, and two of $49(4 \%)$ mantle cell lymphoma (Figure 1). The positive case of follicular lymphoma was grade III and both 
positive cases of mantle cell lymphoma had pleomorphic blastoid morphology. All other B-cell neoplasms were negative, including extranodal marginal zone B-cell lymphoma $(n=11)$, Burkitt lymphoma $(n=10)$, lymphoplasmacytic lymphoma/ Waldenstrom macroglobulinemia $(n=10)$, nodal marginal zone B-cell lymphoma $(n=9)$, precursor B-cell lymphoblastic lymphoma/leukemia $(n=8)$, plasmacytoma $(n=5)$, and splenic marginal zone lymphoma $(n=4)$.

Table 2 summarizes the BCL- 3 results in various types of T-cell lymphoma. Of 111 T-cell lymphomas, $25(23 \%)$ were BCL-3 positive, including 13 of 40 $(32 \%)$ anaplastic large-cell lymphoma, three of 10 $(30 \%)$ angioimmunoblastic T-cell lymphoma, three of $12(25 \%)$ mycosis fungoides, two of eight $(25 \%)$ extranodal NK/T-cell lymphoma of nasal-type, one of five enteropathy-type T-cell lymphoma $(20 \%)$, and two of $21(10 \%)$ peripheral T-cell lymphoma unspecified (Figure 2). All other T-cell neoplasms were negative including precursor T-cell lymphoblastic lymphoma/leukemia $(n=6)$, T-cell

Table 1 BCL-3 expression in 172 cases of B-cell non-Hodgkin lymphoma

\begin{tabular}{lccc}
\hline Subtype & Cases & Positive & $\%$ \\
\hline $\begin{array}{l}\text { Precursor B-lymphoblastic } \\
\text { leukemia/lymphoma }\end{array}$ & 8 & 0 & 0 \\
$\begin{array}{l}\text { Small lymphocytic lymphoma/ } \\
\text { chronic lymphocytic leukemia }\end{array}$ & 17 & 1 & 6 \\
Lymphoplasmacytic lymphoma/ & 10 & 0 & 0 \\
Waldenström macroglobulinemia & & & \\
Follicular lymphoma & 26 & 1 & 4 \\
$\quad$ Grade I & 7 & 0 & \\
Grade II & 9 & 0 & \\
$\quad$ Grade III & 10 & 1 & \\
Marginal zone lymphoma & 24 & 0 & 0 \\
$\quad$ Splenic & 4 & 0 & \\
$\quad$ Nodal & 9 & 0 & \\
$\quad$ Extranodal (MALT-lymphoma) & 11 & 0 & \\
Mantle cell lymphoma & 49 & 2 & 4 \\
Diffuse large B-cell lymphoma & 23 & 6 & 26 \\
Burkitt lymphoma & 10 & 0 & 0 \\
Plasmacytoma & 5 & 0 & 0 \\
\hline
\end{tabular}

prolymphocytic leukemia $(n=6)$, and subcutaneous panniculitis-like T-cell lymphoma $(n=3)$. In anaplastic large-cell lymphomas, BCL-3 expression correlated with ALK-positivity (10/14 ALK + vs 3/26 ALK-; $P=0.015$, Fisher's exact test). All three angioimmunoblastic T-cell lymphomas positive for BCL-3 were relatively high grade with many aggregates of large cells. One of the three positive cases of mycosis fungoides had transformed to large-cell lymphoma ( $>25 \%$ large cells); the other two were consistent with patch $(n=1)$ and plaque $(n=1)$ stage.

Table 3 summarizes BCL-3 results in Hodgkin lymphoma. In 29 of $70(41 \%)$ cases of Hodgkin lymphoma, Reed-Sternberg and Hodgkin cells were positive for BCL-3, including 20 of 43 (47\%) nodular sclerosis, four of $11(36 \%)$ mixed cellularity, one of three lymphocyte-rich classical (33\%), and four of $13(31 \%)$ nodular lymphocyte predominant (Figure 3).

\section{Discussion}

As most prior studies of the $b c l-3$ gene have been performed using molecular genetic methods, and BCL-3 expression has been analyzed infrequently, the aim of this study was to assess for BCL-3 expression in reactive tissues and a wide variety of non-Hodgkin and Hodgkin lymphomas as defined using WHO classification criteria. ${ }^{15}$ We show that a subset of neoplasms in a number of lymphoma types express BCL-3. These neoplasms included Hodgkin lymphoma (41\%), anaplastic large-cell lymphoma (32\%), angioimmunoblastic T-cell lymphoma (30\%), diffuse large B-cell lymphoma (26\%), extranodal NK/T-cell lymphoma of nasal-type (25\%), mycosis fungoides $(25 \%)$, enteropathy-type T-cell lymphoma (20\%), peripheral T-cell lymphoma unspecified (10\%), and rare cases of small lymphocytic lymphoma/chronic lymphocytic leukemia (6\%), follicular lymphoma $(4 \%)$, and mantle cell lymphoma (4\%).

The bcl-3 gene was originally identified by its involvement in the $t(14 ; 19)$. BCL-3 is a member of the $\mathrm{I} \kappa \mathrm{B}$ family that includes at least four other members: $\mathrm{I} \kappa \mathrm{B} \alpha, \mathrm{I} \kappa \mathrm{B} \beta, \mathrm{I} \kappa \mathrm{B} \gamma$, and $\mathrm{I} \kappa \mathrm{B} \varepsilon$. Treatment of
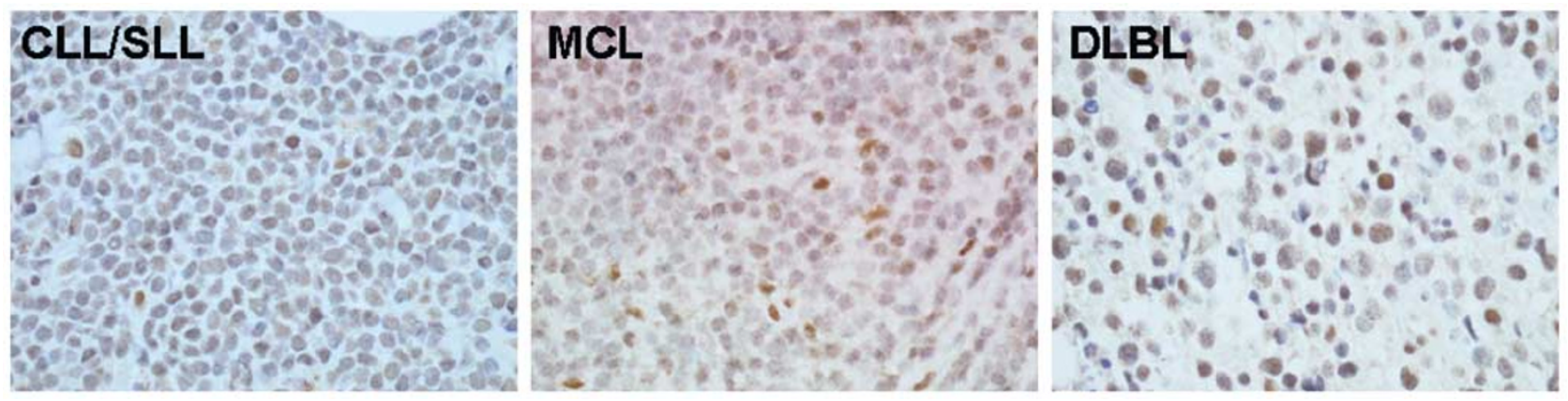

Figure 1 BCL-3 immunoreactivity in B-cell non-Hodgkin lymphomas: a case of chronic lymphocytic leukemia/small lymphocytic lymphoma (CLL/SLL), a case of mantle cell lymphoma (MCL), blastoid variant, and a case of diffuse large B-cell lymphoma (DLBL) are shown (immunoperoxidase with hematoxylin counterstain, original magnification $\times 400$ ). 
Table 2 BCL-3 expression in 111 cases of T-cell non-Hodgkin lymphoma

\begin{tabular}{lccc}
\hline Subtype & Cases & $\begin{array}{c}\text { Positive } \\
(>20 \%)\end{array}$ & $\%$ \\
\hline $\begin{array}{l}\text { Precursor T-lymphoblastic } \\
\text { leukemia/lymphoma }\end{array}$ & 6 & 0 & 0 \\
$\begin{array}{l}\text { T-cell prolymphocytic leukemia } \\
\text { Extranodal NK/T-cell lymphoma, } \\
\text { nasal type }\end{array}$ & 6 & 0 & 0 \\
$\begin{array}{l}\text { Enteropathy-type T-cell } \\
\text { lymphoma }\end{array}$ & 5 & 1 & 20 \\
$\begin{array}{l}\text { Subcutaneous panniculitis-like T- } \\
\text { cell lymphoma }\end{array}$ & 3 & 0 & 0 \\
$\begin{array}{l}\text { Mycosis fungoides } \\
\text { Angioimmunoblastic T-cell }\end{array}$ & 12 & 3 & 25 \\
$\begin{array}{l}\text { lymphoma } \\
\text { Peripheral T-cell lymphoma, }\end{array}$ & 10 & 3 & 30 \\
$\begin{array}{l}\text { Anspecified } \\
\begin{array}{l}\text { ALK (+) } \\
\text { Anaplastic large-cell lymphoma, } \\
\text { ALK (-) }\end{array}\end{array}$ & 14 & 10 & 71 \\
\hline
\end{tabular}

cells with various inducers results in degradation of $\mathrm{I} \kappa \mathrm{B}$ proteins. Although NF- $\kappa \mathrm{B}$ normally exists in inactive form in the cytoplasm of most cells, when $\mathrm{I} \kappa \mathrm{B}$ is degraded, bound $\mathrm{NF}-\kappa \mathrm{B}$ is released and translocated to the nucleus where it activates target genes. $^{4,5}$ Although some of the $\mathrm{I} \kappa \mathrm{B}$ proteins are known to be inhibitors of transcription, it has been shown that BCL-3 interacts with general transcription factors, transcriptional coactivators and also other DNA-binding factors, all of which support a general role for BCL-3 in transcriptional activation. ${ }^{4,5}$

BCL-3 is thought to have many roles. bcl-3 gene expression is induced by many cell growth- or survival-promoting factors in lymphoid cell lines, suggesting that BCL-3 is involved in cell proliferation and survival. ${ }^{19}$ In one study, transgenic mice expressing BCL-3 were found to have an expansion of $\mathrm{B}$-cells in vivo, ${ }^{20}$ further suggesting a role for BCL3 in cell proliferation or survival. On the other hand, BCL-3-deficient mice are susceptible to certain
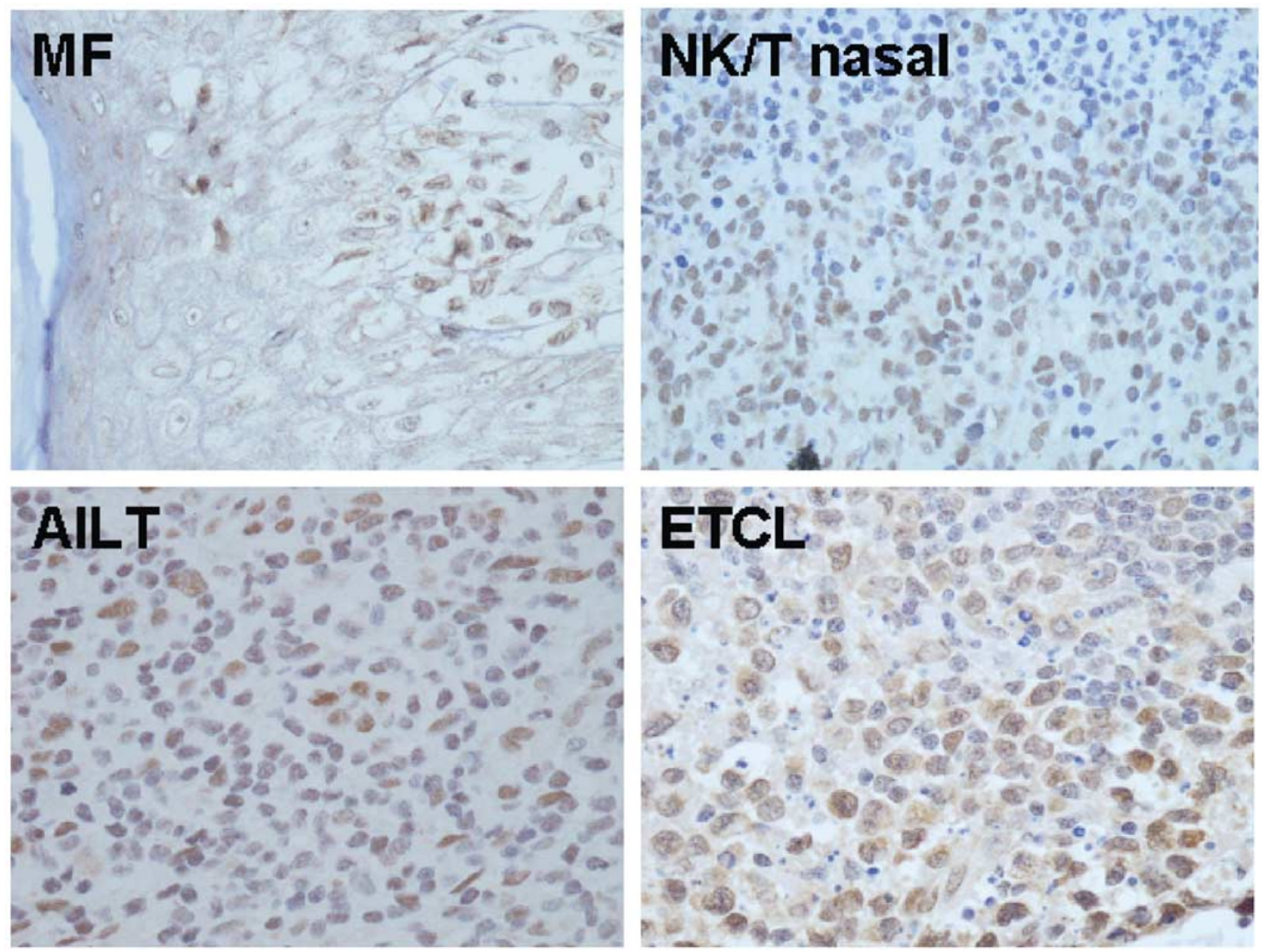

Figure 2 BCL-3 immunoreactivity in T-cell non-Hodgkin lymphomas: a case of mycosis fungoides (MF), plaque stage, a case of extranodal NK/T-cell lymphoma, nasal type (NK/T nasal), a case of angioimmunoblastic T-cell lymphoma (AILT), and a case of enteropathy-type T-cell lymphoma (ETCL) are shown (immunoperoxidase with hematoxylin counterstain, original magnification $\times 400$ ). 
kinds of pathogens, and antigen-specific antibody production was markedly inhibited. Others have hypothesized that bcl-3 directly regulates class switch recombination and somatic hypermutation, because these genetic alterations closely correlate with transcriptional activation of the immunoglobulin genes. ${ }^{21}$ BCL-3 also can bind to the promoter of cyclin D1, enhancing progression of the cell cycle from $\mathrm{G} 1$ to $\mathrm{S}$ phase..$^{4,22}$

Several studies have shown that BCL-3 is activated and may play a role in human breast cancer, ${ }^{23}$ mouse skin carcinogenesis, ${ }^{24}$ and hepatocyte proliferation, ${ }^{25}$ which suggest that BCL-3 is involved in carcinogenesis and cell growth. Additionally, it was reported that BCL-3 affects retinoid X receptor functions in some tissues, and that retinoid $\mathrm{X}$ receptor plays a role in the potential tumorigenesis mediated by BCL- $3 .^{26}$

In this study, diffuse large B-cell lymphoma was the type of B-cell lymphoma most commonly positive for BCL-3, in approximately one-quarter of cases. Au et $a l^{12}$ previously reported four B-cell lymphomas that carried the $\mathrm{t}(14 ; 19)$, including two small lymphocytic lymphoma/chronic lymphocytic leukemia, one diffuse large B-cell lymphoma, and one Burkitt-like lymphoma. They suggested that the cases of diffuse large B-cell and Burkitt-like lymphoma evolved from a prior low-grade small

Table 3 Bcl-3 expression in 70 cases of Hodgkin lymphoma

\begin{tabular}{lrcc}
\hline Subtype & Cases & Positive (>20\%) & $\%$ \\
\hline Nodular lymphocyte predominant & 13 & 4 & 31 \\
Nodular sclerosis & 43 & 20 & 47 \\
Mixed cellularity & 11 & 4 & 36 \\
Lymphocyte-rich classical & 3 & 1 & 33 \\
\hline
\end{tabular}

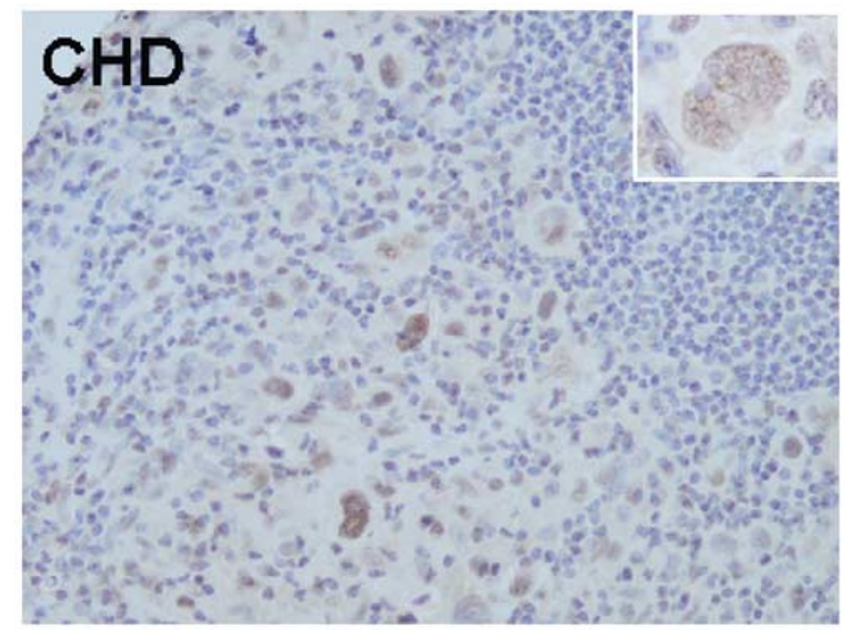

lymphocytic lymphoma/chronic lymphocytic leukemia. In this study, all six diffuse large B-cell lymphomas occurred de novo. Furthermore, in a transgenic mice model, the bcl-3 transgene increased the accumulation of both CD5-positive and CD5-negative B-lymphocytes. ${ }^{20}$ This finding suggests that BCL-3 is involved in the pathogenesis of de novo DLBL, rather than in small lymphocytic lymphoma/chronic lymphocytic leukemia with progression to higher-grade B-cell lymphoma.

In small lymphocytic lymphoma/chronic lymphocytic leukemia, the prevalence of the $t(14 ; 19)$ is low, $<1 \%$ by cytogenetic analysis and ranging from 0 to $2 \%$ by molecular genetic analysis. ${ }^{2,7,12,27-29}$ In these reported cases, aberrant immunophenotype (CD11c expression), atypical morphology, young patient age, and progressive disease were common. ${ }^{2,12,28}$ In this study, BCL-3 positivity was found in one of 17 small lymphocytic lymphoma/chronic lymphocytic leukemia cases assessed. In the BCL-3 positive case, the patient was 65 years old and the morphology was typical. Cytogenetic analysis was not performed on this case.

We detected BCL-3 expression in a subset of cases of many types of T-cell lymphoma. There is precedent for this observation in the literature. BCL-3 expression in interleukin 4-deprived T cells protects these cells from apoptosis. ${ }^{19}$ In anaplastic large-cell lymphoma, a prior study has shown that BCL-3 expression and both genetic and epigenetic modifications of the bcl-3 gene may be associated with oncogenesis. ${ }^{13}$ Izban and colleagues ${ }^{30}$ have reported that NF- $\kappa \mathrm{B}$ p65 is expressed in cutaneous T-cell lymphoma cell lines and neoplastic T lymphocytes from patient samples of mycosis fungoides, and they also showed that nuclear NF- $\kappa \mathrm{B}$ activity is required for cell survival and resistance to apoptosis in the neoplastic cells. Although BCL-3 has a strong preference towards p50 and p52

Figure 3 BCL-3 immunoreactivity in two cases of classical Hodgkin lymphoma (CHD), nodular sclerosis type. Insets: Reed-Sternberg cells positive for BCL-3 (immunoperoxidase with hematoxylin counterstain, original magnification $\times 400$, inset $\times 1000$ ). 
homodimers, in vitro studies have demonstrated that the vertebrate $\mathrm{I} \kappa \mathrm{B}$ family members display different specificities towards NF- $\kappa$ B/Rel proteins. ${ }^{3}$ It is also known that stimuli such as tumor necrosis factor $\alpha$, interleukin $1 \beta$ not only cause nuclear accumulation of p50-p65 heterodimers, but also induce formation of BCL-3-p50 complexes. ${ }^{31}$

The data for B- and T-cell non-Hodgkin lymphomas suggest that BCL-3 expression correlates with cytologic grade (large cell morphology). In B-cell lymphomas, in addition to diffuse large B-cell lymphoma $(26 \%)$, three of the other four positive lymphomas included one grade III follicular lymphoma and two blastoid mantle cell lymphomas. In T-cell lymphomas, BCL-3 was positive in one-third of anaplastic large-cell lymphoma, 30\% of angioimmunoblastic T-cell lymphoma, and approximately a quarter of extranodal NK/T-cell lymphoma of nasaltype and enteropathy-type T-cell lymphoma. In the latter three categories of T-cell lymphoma, all positive neoplasms were composed predominantly of large cells. However, only one of the three BCL-3-positive cases of mycosis fungoides was transformed to large-cell lymphoma. In anaplastic largecell lymphomas, BCL-3 positivity also correlated with ALK expression (71\% ALK + vs 12\% ALK-; $P=0.015$ )

Hodgkin lymphoma was the first hematopoietic tumor in which aberrant constitutive NF- $\kappa \mathrm{B}$ activation was described. In most Hodgkin lymphoma cases, $\mathrm{I} \kappa \mathrm{B} \alpha$ is mutated and expression of RelA/p65 subunit is required for growth of Hodgkin lymphoma. ${ }^{32}$ In our study, approximately $40 \%$ of Hodgkin lymphoma cases were BCL-3 positive. It has been proposed that BCL-3 is an activator of transcription, either by removing p50 homodimers from $\kappa \mathrm{B}$ sites and allowing p65/p50 transactivating complexes to target $\mathrm{DNA}^{33}$ or by coactivation through p50 homodimers. Hinz et $a l^{34}$ reported that cell death protection is a key function of constitutive NF- $\kappa \mathrm{B}$ activity in Reed-Sternberg and Hodgkin cells, but the underlying pathogenesis is more complex. Hinz et al, used large-scale gene profiling to show that NF- $\kappa \mathrm{B}$ regulates a complex network of genes, including signal transducer and activator of transcription (STAT) 5a, interleukin 13, and CC chemokine receptor 7 that are expressed in primary and cultured Reed-Sternberg and Hodgkin cells. ${ }^{34}$

Although almost all BCL-3-positive cases of lymphoma exhibited only a nuclear pattern of positivity, a few cases also showed weaker cytoplasmic positivity in B-cell lymphomas. In addition, rare cases of B-cell lymphoma only had weak cytoplasmic positivity (two diffuse large B-cell lymphoma, two lymphoplasmacytic lymphoma/ Waldenstrom macroglobulinemia and one small lymphocytic lymphoma/chronic lymphocytic leukemia). Whether this staining is true immunoreactivity or background staining is difficult to determine with certainty, but this phenomenon seemed to occur more often in tumors with plasmacytoid differentiation. As the location of BCL-3 protein has been shown to be predominantly nuclear within the cell, we did not consider these rare B-cell lymphomas with only cytoplasmic staining to be truly positive.

In conclusion, we performed an immunohistochemical study for BCL-3 in the 353 cases of nonHodgkin and Hodgkin lymphoma. Our results indicate that a subset of T-cell lymphomas, diffuse large B-cell lymphomas, and Hodgkin lymphomas express BCL-3, in addition to rare cases of small lymphocytic lymphoma/chronic lymphocytic leukemia, high-grade follicular lymphoma, and blastoid mantle cell lymphoma. The relatively high frequency of BCL-3 expression in some lymphoma types raises the possibility that BCL-3 plays an oncogenetic role in development of these neoplasms, and may be a potential target for investigational therapies.

\section{References}

1 Bloomfield CD, Arthur DC, Frizzera G, et al. Nonrandom chromosome abnormalities in lymphoma. Cancer Res 1983;43:2975-2984.

2 Ueshima Y, Bird ML, Vardiman JW, et al. A 14;19 translocation in B-cell chronic lymphocytic leukemia: a new recurring chromosome aberration. Int J Cancer 1985;36:287-290.

3 McKeithan TW, Rowley JD, Shows TB, et al. Cloning of the chromosome translocation breakpoint junction of the $t(14 ; 19)$ in chronic lymphocytic leukemia. Proc Natl Acad Sci USA 1987;84:9257-9260.

4 Orlowski RZ, Baldwin AS. NF- $\kappa$ B as a therapeutic target in cancer. Trends Mol Med 2002;8:385-389.

5 Dechend R, Hirano F, Lehmann K, et al. The Bcl-3 oncoprotein acts as a bridging factor between $\mathrm{NF}-\kappa \mathrm{B} / \mathrm{Rel}$ and nuclear co-regulators. Oncogene 1999; 18:3316-3323.

6 Tanaka S, Nishigaki H, Nakagawa H, et al. Reciprocal $\mathrm{t}(14 ; 19)(\mathrm{q} 32.3 ; \mathrm{q} 13.1)$ in a patient with B-cell lymphoma. Cancer Genet Cytogenet 1990;49:219-224.

7 Van Krieken JHJM, McKeithan TW, Raghoebiar S, et al. Chromosomal translocation $\mathrm{t}(14 ; 19)$ as indicated by bcl-3 rearrangement is a rare phenomenon in nonHodgkin's lymphoma and chronic lymphocytic leukemia: a molecular genetic analysis of 176 cases. Leukemia 1990;4:811-812.

8 Carter R, Dubé I, McKeithan T, et al. Translocation $(14 ; 19)$ in acute biphenotypic leukemia. Cancer Genet Cytogenet 1991;53:67-73.

9 Solé F, Woessner S, Florensa L, et al. A new case of $\mathrm{t}(14 ; 19)(\mathrm{q} 32 ; \mathrm{q} 13)$ in a patient with follicular lymphoma in leukemic phase. Cancer Genet Cytogenet 1994;75:72-73.

10 Michaux L, Dierlamm J, Wlodarska I, et al. t(14;19)/ BCL-3 rearrangements in lymphoproliferative disorders: a review of 23 cases. Cancer Genet Cytogenet 1997;94:36-43.

11 McKeithan TW, Takimoto GS, Ohno H, et al. BCL3 rearrangements and $\mathrm{t}(14 ; 19)$ in chronic lymphocytic leukemia and other B cell malignancies: a molecular 
and cytogenetic study. Genes Chromosomes Cancer 1997;20:64-72.

$12 \mathrm{Au}$ WY, Horsman DE, Ohno $\mathrm{H}$, et al. Bcl-3/IgH translocation $(14 ; 19)(q 32 ; q 13)$ in non-Hodgkin's lymphomas. Leuk Lymphoman 2002;43:813-816.

13 Nishikori M, Maesako Y, Ueda C, et al. High-level expression of BCL-3 differentiates $t(2 ; 5)(p 23 ; q 35)-$ positive anaplastic large cell lymphoma from Hodgkin disease. Blood 2003;101:2789-2796.

14 Rassidakis GZ, Oyarzo MP, Medeiros LJ. BCL-3 overexpression in anaplastic lymphoma kinase-positive anaplastic large cell lymphoma. Blood 2003;102: 1146-1147.

15 Jaffe ES, Harris NL, Stein H, Vardiman JW, (eds). Pathology and Genetica of Tumours of Haematopoietic and Lymphoid Tissues, World Health Organization Classification of Tumours. IARC Press: Lyon, 2001.

16 Rassidakis GZ, Jones D, Thomaides A, et al. Apoptotic rate in peripheral T-cell lymphomas: a study using a tissue microarray with validation on full tissue sections. Am J Clin Pathol 2002;118:328-334.

17 Khoury JD, Medeiros LJ, Rassidakis GZ, et al. Differential expression and clinical significance of tyrosinephosphorylated STAT3 in ALK+ and ALK - anaplastic large cell lymphoma. Clin Cancer Res 2003;9: 3692-3699.

18 Khoury JD, Medeiros LJ, Rassidakis GZ, et al. Expression of MCL-1 in mantle cell lymphoma is associated with high-grade morphology, a high proliferative state, and p53 overexpression. J Pathol 2003;199:90-97.

19 Rebollo A, Dumoutier L, Renauld J-C, et al. Bcl-3 expression promotes cell survival following interleukin-4 deprivation and is controlled by AP1 and AP1-like transcription factors. Mol Cell Biol 2000;20: 3407-3416.

20 Ong ST, Hackbarth ML, Degenstein LC, et al. Lymphadenopathy, splenomegaly, and altered immunoglobulin production in BCL-3 transgenic mice. Oncogene 1998;16:2333-2343.

21 Honjo T, Kinoshita K, Muramatsu M. Molecular mechanism of class switch recombination: linkage with somatic hypermutation. Annu Rev Immunol 2002;20:165-196.

22 Westerheide SD, Mayo MW, Anest V, et al. The putative oncoprotein Bcl-3 induces cyclin D1 to simulate $G_{1}$ transition. Mol Cell Biol 2001;21: 8428-8436.
23 Cogswell PC, Guttridge DC, Funkhouser WK, et al. Selective activation of NF- $\kappa$ B subunits in human breast cancer: potential roles for NF- $\kappa \mathrm{B} 2 / \mathrm{p} 52$ and for Bcl-3. Oncogene 2000;19:1123-1131.

24 Budunova IV, Perez P, Vaden VR, et al. Increased expression of p50-NF-kappaB and constitutive activation of NF-kappaB transcription factors during mouse skin carcinogenesis. Oncogene 1999;9:7423-7431.

25 Feng X, Jiang Y, Meltzer P, et al. Transgenic targeting of a dominant negative corepressor to liver blocks basal repression by thyroid hormone receptor and increases cell proliferation. J Biol Chem 2001;276 15066-15072.

26 Na S-Y, Choi H-S, Kim JW, et al. Bcl-3, an I $\kappa$ B protein, as a novel transcription coactivator of retinoid $\mathrm{X}$ receptor. J Biol Chem 1998;273:30933-30938.

27 Asou H, Takechi M, Tanaka K, et al. Japanese B cell chronic lymphocytic leukemia: a cytogenetic and molecular biological study. Br J Haematol 1993;85: 492-497.

28 Michaux L, Mecucci C, Stul M, et al. BCL-3 rearrangement and $\mathrm{t}(14 ; 19)(\mathrm{q} 32 ; \mathrm{q} 13)$ in lymphoproliferative disorders. Genes Chromosome Cancer 1996;15:38-47.

29 Munzert G, Kreitmeier S, Bergmann L. Normal structure of NFKB2, C-REL, and BCL-3 gene loci in lymphoproliferative and myeloproliferative disorders. Leuk Lymphoma 2000;38:395-400.

30 Izban KF, Ergin M, Qin J-Z, et al. Constitutive expression of $\mathrm{NF}-\kappa \mathrm{B}$ is a characteristic feature of mycosis fungoides: implications for apoptosis resistance and pathogenesis. Hum Pathol 2000;31: 1482-1490.

31 Heissmeyer, Krappmann D, Wulczyn FG, et al. NF- $\kappa \mathrm{B}$ p105 is a target of $I \kappa B$ kinases and controls signal induction of Bcl-3-p50 complexes. EMBO J 1999;18: 4766-4778.

32 Cabannes E, Khan G, Aillet F, et al. Mutations in the $\mathrm{I} \kappa \mathrm{B} \alpha$ gene in Hodgkin's disease suggest a tumour suppressor role for $\mathrm{I} \kappa \mathrm{B} \alpha$. Oncogene 1999;18:3063-3070.

33 Franzoso G, Bours V, Park S, et al. The candidate oncoprotein Bcl-3 is an antagonist of p50/NF- $\kappa \mathrm{B}$ mediated inhibition. Nature 1992;359:339-342.

34 Hinz M, Lemke P, Anagnostopoulos I, et al. Nuclear factor $\kappa \mathrm{B}$-dependent gene expression profiling of Hodgkin's disease tumor cells, pathogenetic significance, and link to constitutive signal transducer and activator of transcription 5a activity. J Exp Med 2002;196:605-617. 